\title{
Optimizing the fermentation condition of low salted squid jeotgal by lactic acid bacteria with enhanced antioxidant activity
}

\author{
Fahima Akther ${ }^{1} \cdot$ Bao Le $^{2} \cdot$ Gyuhwa Chung $^{2}$ Seung Hwan Yang ${ }^{2}$ (D)
}

Received: 8 September 2017 / Accepted: 14 November 2017 / Published Online: 31 December 2017

(C) The Korean Society for Applied Biological Chemistry 2017

\begin{abstract}
Lactic acid bacteria (LAB) are widely used as starter culture in food fermentation due to their harmless entity and health beneficial properties along with the ability to change texture, aroma, flavor and acidity of food products. In this study, five different LAB (FB003, FB058, FB077, FB081, and FB111) isolated from different Korean traditional fermented foods, assigned to Lactobacillus plantarum, Pediococcus pentosaceus, Weissella viridescens, Lactobacillus sakei, and Leuconostoc mesenteroides, respectively, on the basis of their physiological properties and 16S rRNA sequence analysis, to use as fermentation starter and check their ability to fasten the ripening time as well as the overall optimization in the fermentation condition. To check their suitability as starters, their safety, acid and bile tolerance, $\mathrm{NaCl}$ and temperature resistance, susceptibility to common antibiotics, and antimicrobial activities were determined. Squid jeotgal samples were prepared by adding $10^{8} \mathrm{CFU} / \mathrm{g}$ of each strain in different samples, which were then kept for fermentation at $4{ }^{\circ} \mathrm{C}$ and checked for their antioxidant activities at $0,7,15$, and 21-day intervals. The samples fermented with FB003 and FB077 displayed the highest antioxidant activity. This study revealed two effective starter cultures (FB003, FB077) for squid jeotgal fermentation, which presented increased functionalities. The results of this study will lead to the development of novel industrial-scale production avenues for jeotgal preparation, and offer new insights into the prevention and control of chronic diseases.
\end{abstract}

Seung Hwan Yang $(\varangle)$

E-mail: ymichigan@jnu.ac.kr

${ }^{1}$ Department of Biomedical Engineering, Chonnam National University, Yeosu, Chonnam 59626, Republic of Korea

${ }^{2}$ Department of Biotechnology, Chonnam National University, Yeosu, Chonnam 59626, Republic of Korea

This is an Open Access article distributed under the terms of the Creative Commons Attribution Non-Commercial License (http://creativecommons. org/licenses/by-nc/3.0/) which permits unrestricted non-commercial use, distribution, and reproduction in any medium, provided the original work is properly cited.
Keywords Antibiotics - Antioxidant · Fermentation - Lactic acid bacteria $\cdot$ Squid jeotgal

\section{Introduction}

In recent years, due to the increase in health awareness and new developments in the field of nutritional science, consumers are willing to seek healthier foods, with a number of functionalities. Due to the growing number of chronic diseases, including agerelated disorders, cancer, cardiovascular and digestive tract problems, health has become the most serious concern behind the consumer's food choices. The use of food products to prevent or cure various diseases does not represent a new concept. Specific food items have been traditionally used for medical purposes in different cultures (Cencic and Chingwaru 2010) and are known as 'functional foods' in the modern age.

Jeotgal is one of the traditional, ready to eat, fermented functional sea foods in the Korean cuisine, made by using the whole meat and/or only the internal part, or any specific part of shrimp, fish, shellfish, oyster, crabs, squid, and octopus. It can be consumed as a fermented seafood by itself, or as a condiment additive in other foods including pickles, kimchi, or soup, for improving taste (Lee et al. 2014). In jeotgal, fermentation and salting inhibit the spoilage, autolysis, and decomposition of the main ingredients through microbial activity (Koo et al. 2016), while the decomposition of raw components by beneficial organisms leads to a unique flavor. Therefore, research and development efforts have focused on jeotgal, based on the consumers' demand, and have shown that jeotgal has an outstanding potential to be globally recognized as a nutritious and palatable food product.

Lactic acid bacteria (LAB) represent a group of gram-positive, non-sporulating, anaerobic or facultative aerobic cocci or rods, which produce lactic acid as one of the main fermentation products of the carbohydrate metabolism (Hayek and Ibrahim 2013). LAB are industrially important organisms, due to their fermentative ability, as well as their health and nutritional benefits. 
The potential health benefits of LAB in the human body include the stimulation of the immune system, balancing the intestinal flora, reducing the serum cholesterol levels, and reducing the risk of tumors, as well as anti-ageing and antioxidant activities (Ayeni et al. 2011; Kuda et al. 2010; Lee et al. 2010). In the food industry, LABs are widely used as starters to achieve favorable changes in texture, aroma, flavor, and acidity (Leroy and De Vuyst 2004). Fermentation using LAB improves the nutritional value of food products, increasing the quantity, availability, digestibility, and assimilation of nutrients. The essential roles of $\mathrm{LAB}$ are the inhibition of food spoilage and the growth inhibition of pathogenic bacteria, thus improving the safety and shelf life of food products (Ljungh and Wadstrom 2006).

Reactive oxygen species (ROS) and other free radicals are derived either from endogenous metabolic processes in the human body, or from external sources (Hajhashemi et al. 2010). They have been recognized as important factors in the pathogenesis of several human diseases, since they cause protein degradation, DNA mutations, the oxidation of membrane phospholipids, and the modification of low-density lipoproteins (Serafini and Del Rio 2004). Antioxidants, molecules that safely react with free radicals, can only limit the adverse effects of ROS by neutralizing or terminating the chain reaction before vital molecules are damaged (Bagchi and Puri 1998).

With the development of the functional food concept, in recent years, many studies have shown that the regular consumption of antioxidant rich foods may help to reduce the detrimental action of ROS and free radicals, by balancing oxidative stress, which is related to aging and chronic illnesses (Serafini and Del Rio 2004). Currently, this idea promotes a growing trend of modifying eating habits to fight against illness and improve the nutritional status of consumers (Frei 2004).

In this study, the main focus was to increase the functional value of squid jeotgal with rapid fermentation index by using lactic acid bacteria as fermentation starters, and analyzed the antioxidant activities of squid jeotgal at different time intervals ( 0 days, 7 days, 15 days, and 21 days). To investigate the antioxidant activity, a series of assays were performed: the 2,2-diphenyl-1picryl hydrazyl (DPPH) free radical scavenging activity assay, the 2,2-azino-bis (3-ethylbenzothiazoline-6-sulfonic acid (ABTS) diammonium salt) radical cation scavenging activity assay, and a reducing power assay. The samples fermented with FB003 and FB077 displayed the highest antioxidant activity which may lead to the development of novel industrial-scale production avenues for squid jeotgal, and offer new insights into the prevention and control of chronic diseases.

\section{Materials and Method}

Microbial strains and culture media

LAB were isolated from Korean traditional fermented foods, including kimchi and different types of jeotgal, collected from the local food market in Yeosu, South Korea. The samples were stored at $4{ }^{\circ} \mathrm{C}$ until further processing. One percent of each fermented food sample was serially diluted in distilled water, and $100 \mu \mathrm{L}$ of the appropriate dilutions were plated on de Man Rogosa and Sharpe (MRS) agar medium (Becton, Dickinson Co., Sparks, MD, USA) and incubated at $37^{\circ} \mathrm{C}$ for $24 \mathrm{~h}$, for picking single colonies. The strains were stored as glycerol stocks $(25 \%$ glycerol in MRS broth) at $-80{ }^{\circ} \mathrm{C}$.

The pathogenic microbes used in this study were obtained from the Korean Collection for Type Cultures (KCTC), KACC, and Korean Culture Center of Microorganisms (KCCM), Republic of Korea. Escherichia coli K99 (KCTC 2617), Shigella boydii (KACC 10792), Staphylococcus aureus (KCCM 11335), Listeria monocytogenes (KACC 10764) and Yersinia enterocolitica (KACC 15320) were used in our study. The pathogenic strains were routinely cultured in BHI (Brain-heart infusion) agar medium and stored as glycerol stocks ( $25 \%$ glycerol in BHI broth, v/v) at $-80{ }^{\circ} \mathrm{C}$.

\section{Identification of strains}

The initial identification of the isolates was done by using gram staining, microscopic examination, and the carbohydrate fermentation test, using API $50 \mathrm{CH}$ carbohydrate fermentation strips (bioMerieux, Craponne, France), and was based on phenotypical characteristics (Brolazo et al. 2011). The results were analyzed according to the biochemical profiles registered in the APIweb $^{\circledR}$ database (bioMerieux). Genomic DNA for the selected strains was isolated by using a genomic DNA isolation kit (GeneALL, Seoul, Korea), following the manufacturer's protocol. The 16S rRNA gene was PCR amplified from five selected isolates with the 27F and 1492R primers (Borges et al. 2013). and sequenced with the $27 \mathrm{~F}$ and 785F (5'-GGATTAGATACCCTGGTA-3') primers to obtain a partial sequence of the 16S rRNA gene. The sequences were compared to ones in the GenBank nucleotide database, using the BLAST program and a neighbor-joining phylogenetic tree was constructed using MEGA 6 software (Damodharan et al. 2015).

\section{Safety assessment of the selected strains}

The biogenic amine production of the selected strains was determined according to Bover-Cid and Holzapfel (1999) using decarboxylase medium with or without amino acids, such as Ltyrosine, L-histidine, L-ornithine, L-arginine, L-phenylalanine, Llysine, or L-tryptophan. Mucin degradation was examined according to Zhou et al. (2001) by using $0.3 \%$ mucin supplied agarose medium with or without glucose. Finally, hemolytic activity was tested using MRS agar medium, supplied with 5\% defibrinated sheep blood (Leite et al. 2015). The minimum inhibitory concentration (MIC) of antibiotics of the isolates was tested using the antibiotics recommended by EFSA, following a 2fold broth microdilution method. 
In vitro assessment of the selected strains for gastrointestinal tract survival

The acid tolerance assay was performed according to Ehrmann et al. (2002), with slight modifications. Approximately 7 to $8 \log _{10}$ $\mathrm{CFU} / \mathrm{mL}$ from each overnight culture of the isolates were incubated into $(1 \%, \mathrm{v} / \mathrm{v})$ sterile phosphate buffer saline (PBS) and adjusted to $\mathrm{pH}-2$ and $\mathrm{pH}-3$ with $1 \mathrm{~N} \mathrm{HCl}$. PBS with a normal $\mathrm{pH}$ of 7.2 was used as the control. Next, the isolates were incubated in an anaerobic jar for $3 \mathrm{~h}$ at $37{ }^{\circ} \mathrm{C}$. After incubation, $100 \mu \mathrm{L}$ of the $10^{-4}$ to $10^{-7}$ dilutions from each sample were spread-plated onto MRS agar, and incubated anaerobically at $37{ }^{\circ} \mathrm{C}$ for $24 \mathrm{~h}$. The colonies on the plates were counted and expressed as CFU/ $\mathrm{mL}$. The tolerance to acidic conditions was estimated by comparing viable cell counts after exposure to acidic ( $\mathrm{pH}-2$ and $\mathrm{pH}-3$ ) and normal (control) conditions.

The bile tolerance assay was tested according to Shobharani et al. (2013), with modifications. Overnight cultures for each of the $\mathrm{LAB}$ strains, adjusted to a final concentration of 7 to $8 \log _{10} \mathrm{CFU} /$ $\mathrm{mL}$, were inoculated $(1 \%, \mathrm{v} / \mathrm{v})$ into $10 \mathrm{~mL}$ of fresh MRS broth, with or without (control) $0.3 \%(\mathrm{w} / \mathrm{v})$ oxgall, and incubated at 37 ${ }^{\circ} \mathrm{C}$ in an anaerobic jar for $4 \mathrm{~h}$ and after incubation, $100 \mu \mathrm{L}$ of the $10^{-4}$ to $10^{-7}$ dilutions from each sample were spread-plated onto MRS agar, and incubated anaerobically at $37^{\circ} \mathrm{C}$ for $24 \mathrm{~h}$. After incubation, the viability of the bacterial cells was assessed by counting the colonies $(\mathrm{CFU} / \mathrm{mL})$ on the plates. Bile tolerance was estimated by comparing the viable cell counts in MRS, in the presence or absence of bile (oxgall).

The tolerance to pancreatic enzymes was determined using the method of Rönkä et al. (2003) with several modifications. The harvested cell pellet of the overnight culture for each selected strain was resuspended in PBS to a final concentration of 7 to 8 $\log _{10} \mathrm{CFU} / \mathrm{mL}$, and $1 \%(\mathrm{v} / \mathrm{v})$ of the resuspended cells was inoculated into $10 \mathrm{~mL}$ of test solution (PBS containing $150 \mathrm{mM}$ $\mathrm{NaHCO}_{3}$ and $1.9 \mathrm{mg} / \mathrm{mL}$ pancreatin) and control solution (PBS, $\mathrm{pH}-7.2)$. The cultures were incubated in an anaerobic jar at $37{ }^{\circ} \mathrm{C}$ for 3 h. $100 \mu \mathrm{L}$ of the $10^{-4}$ to $10^{-7}$ dilutions from each sample were spread-plated on MRS agar. The plates were incubated anaerobically at $37{ }^{\circ} \mathrm{C}$ for $24 \mathrm{~h}$, after which the viability of the bacterial cells was assessed by counting colonies (CFU/mL). The tolerance to pancreatic enzymes was estimated by comparing the viable cell counts in the test and the control solutions.

\section{Resistance to $\mathrm{NaCl}$ and temperature}

Based on the protocol of Menconi et al. (2014), with slight modifications, an overnight culture of each of the selected isolates was centrifuged at $5000 \times \mathrm{g}$ for $10 \mathrm{~min}$ and resuspended in $0.85 \%$ sterile saline, to prepare the inoculums. A volume of $100 \mu \mathrm{L}$ of suspension, for each inoculum, was inoculated into $10 \mathrm{~mL}$ of MRS broth. The temperatures tested were 15 and $45{ }^{\circ} \mathrm{C}$ and the cultures were incubated for $4 \mathrm{~h}$. The concentrations of $\mathrm{NaCl}$ tested were 2,4 and $6.5 \%(\mathrm{w} / \mathrm{v})$. The tubes were anaerobically incubated at $37{ }^{\circ} \mathrm{C}$ for $4 \mathrm{~h}$, for testing the concentrations of $\mathrm{NaCl}$. The tolerance to $\mathrm{NaCl}$ and temperature was tested by streaking each sample onto MRS agar, to determine the presence or absence of growth, which was used to confirm the viability of the strains.

\section{Antimicrobial activity of selected isolates}

The cell free supernatant (CFS) was prepared according to the procedure described by Müller et al. (2009). One hundred microliters of CFS were loaded onto an 8-mm paper disc and dried. The preloaded disc was placed on BHI agar plates, spread with overnight cultures of the tested pathogens. After 18 to $24 \mathrm{~h}$ incubation, the zone of inhibition was measured. The entire assay was performed in triplicate, to check the reproducibility of the method.

\section{Starter culture preparation}

The starter cultures were prepared by using five selected strains, FB003, FB058, FB077, FB081 and FB111, according to Akabanda et al. (2014), with some modifications. The LAB strains used as inocula were prepared by transferring a loopful of an overnight culture from MRS agar into MRS broth, which was then anaerobically incubated at $37{ }^{\circ} \mathrm{C}$ for $24 \mathrm{~h}$. Next, $1 \%$ (v/v) of the 24-h old culture was transferred into MRS broth, and again incubated anaerobically at $37^{\circ} \mathrm{C}$ for $16-18 \mathrm{~h}$. The ODs of the five isolates were checked and adjusted at $10^{8} \mathrm{CFU} / \mathrm{mL}$. Thereafter, cells were harvested by centrifugation (Avanti ${ }^{\mathrm{TM}} \mathrm{J}-25 \mathrm{I}$, Beckman Coulter, California, USA) at $5000 \times g$ for $10 \mathrm{~min}$ at $4{ }^{\circ} \mathrm{C}$, washed

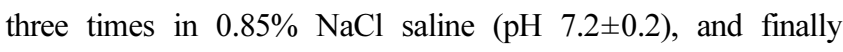
resuspended into $0.85 \% \mathrm{NaCl}$ saline.

\section{Squid jeotgal sample preparation and fermentation}

Squid jeotgal was prepared under sterile conditions, in the laboratory, by using fresh and small squid, collected from the Yeosu fish market in South Korea. The low salt seasoning containing hot pepper flakes, salt (2-2.5\%) and 20 different types of herbs, was supplied by Greenmin Food co. at Yeosu in South Korea. We also followed this company's procedure for the preparation of our samples, by adding squid and seasoning (3:1 w/ w). A thick sample paste was obtained by using a food processor. The starter culture suspension prepared previously was then added to the sample paste at $10^{8} \mathrm{CFU} / \mathrm{g}$. Starter cultures from each of the five selected isolates (FB003, FB058, FB077, FB081, and FB111) were mixed separately with the squid jeotgal sample paste, and maintained for fermentation in air tight containers at $4{ }^{\circ} \mathrm{C}$ for 0,7 , 15 , and 20 days; the activities of these samples were compared with the activities of the sample in the absence of the starter culture. Samples were named according to the respective starter culture strains.

The working soluble fraction of fermented squid jeotgal was prepared by following the procedure described by Prapasuwannakul and Suwannahong 2015 with slight modifications. Five grams of the fermented sample paste mixed with different isolates was added to the solvent (containing 70\% ethanol: $5 \%$ DMSO: $25 \%$ 
water) in a $1: 10 \mathrm{v} / \mathrm{v}$ ratio, and stirred for $3 \mathrm{~h}$ at room temperature $\left(25{ }^{\circ} \mathrm{C}\right)$. The mixture was centrifuged at $5000 \mathrm{rpm}$ for $10 \mathrm{~min}$ using a refrigerated centrifuge, to remove debris. The supernatant was used for further analysis.

\section{Determining the viability rate of lab in fermented samples}

The viability rates of LAB in fermented samples, at different time intervals $(0,7,15,21)$, were determined using the plate counting method. One gram of the sample was diluted in $10 \mathrm{~mL}$ sterile distilled water, according to Lucio et al. (Lucio et al. 2017), with some modifications. For plate counts, serial dilutions of starter suspensions were carried out, and these were plated on MRS plates. Then the plates were incubated at $37{ }^{\circ} \mathrm{C}$ for $24 \mathrm{~h}$. The number of viable bacteria in the fermented samples, expressed as $\mathrm{CFU} / \mathrm{mL}$, was obtained by counting the isolated colonies on these plates.

\section{Antioxidant Assays}

The DPPH radical scavenging activity was determined using the DPPH assay, as previously described by Gyamfi et al. (1999), with slight modifications. Each extract $(20 \mu \mathrm{L})$ was mixed with $200 \mu \mathrm{L}$ of DPPH methanolic solution $(100 \mu \mathrm{M})$. The blank was prepared by using the same volume of methanol, instead of the DPPH working solution, for all samples. Then, the mixture was mixed vigorously and allowed to sit at room temperature for 30 min in the dark. The absorbance of the resulting solution was measured at $517 \mathrm{~nm}$ against a blank. The control was prepared in the same manner, except that working solvent (70\% ethanol: $0.5 \%$ DMSO) was used instead of the sample. Blank values were subtracted from the test values. Ascorbic acid was used as a positive control.

The scavenging activity was calculated using the following formula:

$$
\mathrm{DPPH}^{*} \text { scavenging activity }=\left(1-A_{\text {sample }} / A_{\text {control }}\right) \times 100 \%
$$

ABTS radical scavenging activity was determined using the ABTS assay, following the method described by Re et al. (1999), with slight modifications. The stock solutions included $7 \mathrm{mM}$ ABTS solution and $2.45 \mathrm{mM}$ potassium persulfate solution. The working solution was prepared by mixing the two stock solutions in equal quantities, and allowing them to react for $12-16 \mathrm{~h}$ at room temperature, in the dark. The solution was then diluted by adding distilled water, in order to obtain an $\mathrm{OD}_{734 \mathrm{~nm}}=0.7$, measured using a UV-spectrophotometer. Fresh ABTS solution was prepared for each assay. A sample $(10 \mu \mathrm{L})$ was mixed with $1 \mathrm{~mL}$ of working ABTS solution, and the mixture was left at room temperature for 5-10 min. The blank was prepared by using the same volume of methanol, instead of the ABTS working solution, for all samples. The absorbance was then measured at $734 \mathrm{~nm}$, against the blank, using the spectrophotometer. The control was prepared in the same manner, except that working solvent (70\% ethanol: $0.5 \%$ DMSO) was used instead of the sample. Blank values were subtracted from the test values. Ascorbic acid was used as a positive control.

The scavenging activity was calculated using the following formula:

$$
\text { ABTS* scavenging activity }=\left(1-A_{\text {sample }} / A_{\text {control }}\right) \times 100 \%
$$

The reducing power was determined according to Oyaizu (1986), with slight modifications. A $1-\mathrm{mL}$ volume of the sample extract was mixed with $1 \mathrm{~mL}$ of $200 \mathrm{mM}$ sodium phosphate buffer $(\mathrm{pH}$ $6.6)$, and $1 \mathrm{~mL}$ of $1 \%(10 \mathrm{mg} / \mathrm{mL})$ potassium ferricyanide was added to the mixture. The mixture was incubated at $50{ }^{\circ} \mathrm{C}$ for 20 min. After cooling down, $1 \mathrm{~mL}$ of $10 \%$ trichloroacetic acid (w/v) was added to each sample, and the mixture was centrifuged at $6500 \mathrm{rpm}$ for $10 \mathrm{~min}$. A 2-mL volume of the supernatant was mixed with $2 \mathrm{~mL}$ of distilled water, and $400 \mu \mathrm{L}$ of $0.1 \%$ ferric chloride. The absorbance was measured at $700 \mathrm{~nm}$. Ascorbic acid was used as the reference standard. A higher absorbance indicated a higher reducing power.

\section{Statistical analysis}

All tests were performed at least three times. Means were compared using analysis of variance (ANOVA), and significant differences were analyzed using the SPSS ver. 22 software (IBM SPSS statistics, New York, NY, USA) (EFSA 2012). The results are expressed as the mean \pm standard deviation (SD). A difference was considered statistically significant at $p \leq 0.05$.

\section{Results and Discussion}

The popularity of low salted squid jeotgal is increasing day by day. Due to the consciousness of health, consumers are willing to take food not only to fulfill appetite also as disease preventative. According to the global demand of fermented food market, shorttime fermented foods also holding a great share in present time. To improve the fermentation condition and fastening the fermentation time starter culture incorporation in the fermentation process gaining acceptability where starter culture also works to improve the food status with enhanced functionalities. Biochemical characterization and genetic confirmation of the selected strains

The carbohydrate fermentation pattern of the five strains, examined using the API $50 \mathrm{CH}$ kit, determined that different strains showed different carbohydrate fermentation profiles, but all strains showed homo fermentation patterns (Table 1). The results of the comparative $16 \mathrm{~S}$ rRNA gene analysis for all five strains, from different fermented food sources are shown in Table 2. All isolates displayed $99 \%$ similarity to their nearest matched species from GenBank and the phylogenic tree constructed based on 16S rRNA sequence was shown in Fig. 1. All five selected samples used in our experiment-FB003 (Lactobacillus plantarum), FB058 (Pediococcus pentosaceus), FB077 (Weissella viridescens), FB081 (Lactobacillus sakei), and FB111 (Leuconostoc mesenteroides)- 
Table 1 Carbohydrate fermentation pattern of five selected strains by using API $50 \mathrm{CH}$ kit

\begin{tabular}{|c|c|c|c|c|c|}
\hline Carbohydrates & FB003 & FB058 & FB077 & FB081 & FB111 \\
\hline Temoin & - & - & - & - & - \\
\hline Glycerol & \pm & - & - & - & - \\
\hline Erythritol & - & - & - & - & - \\
\hline D-Arabinose & - & - & - & - & - \\
\hline L-Arabinose & + & + & \pm & + & \pm \\
\hline D-Ribose & + & + & & + & \pm \\
\hline D-Xylose & - & - & \pm & - & + \\
\hline L-Xylose & - & - & - & - & - \\
\hline Adonitol & - & - & - & - & - \\
\hline Methyl- $\beta$-D-xylopyranoside & - & - & - & - & - \\
\hline Galactose & + & + & + & + & - \\
\hline Glycose & + & + & + & + & + \\
\hline Fructose & + & + & + & + & + \\
\hline Mannose & + & + & \pm & + & + \\
\hline Sorbose & - & - & - & - & - \\
\hline Rhamnose & - & - & - & - & - \\
\hline Dulcitol & - & - & - & - & - \\
\hline Inositol & - & - & - & - & - \\
\hline Mannitol & + & - & + & - & - \\
\hline D-Sorbitol & + & - & - & - & - \\
\hline $\begin{array}{l}\text { Methyl- } \alpha \text {, } \\
\text { D-mannopyranoside }\end{array}$ & + & - & - & - & - \\
\hline Methyl- $\alpha$, D-glycoside & - & - & - & & - \\
\hline N-Acetyl-glucosamine & + & + & + & + & - \\
\hline Amygdalin & + & + & - & - & - \\
\hline Arbutin & + & + & + & - & - \\
\hline Esculin & + & + & + & + & + \\
\hline Salicin & + & + & - & + & \pm \\
\hline Cellobiose & + & - & - & + & + \\
\hline Maltose & + & + & + & + & + \\
\hline Lactose & + & + & - & + & - \\
\hline Melibiose & + & + & - & + & + \\
\hline Sucrose & + & + & - & + & + \\
\hline Trehalose & + & - & + & + & + \\
\hline Inulin & - & - & - & - & - \\
\hline Melezitose & + & - & - & - & - \\
\hline Raffinose & + & + & - & - & + \\
\hline Starch & - & - & - & - & - \\
\hline Glycogen & - & - & - & - & - \\
\hline Xylitol & - & - & - & - & - \\
\hline Gentiobiose & + & + & - & - & \pm \\
\hline D-Turanose & + & - & - & + & - \\
\hline D-Lyxose & - & - & - & - & + \\
\hline D-Tagatose & - & + & - & - & - \\
\hline D-Fucose & - & - & - & - & - \\
\hline L-Fucose & - & - & - & - & - \\
\hline D-Arabitol & - & - & - & - & - \\
\hline L-Arabitol & - & - & - & - & - \\
\hline Glyconate & + & - & + & + & \pm \\
\hline 2-keto-Gluconate & + & - & - & - & \pm \\
\hline 5-keto-Gluconate & + & - & - & - & - \\
\hline Fermentation Pattern & Homo & Homo & Homo & Homo & Homo \\
\hline
\end{tabular}

Carbohydrate fermentation pattern of five selected strains in API $50 \mathrm{CH}$ kit; +, positive carbohydrate utilization; \pm , moderate utilization; -, no utilization. *Green color colonies on HHD medium indicates homo fermentative pattern showed high safety profiles, which ensured that no undesirable reaction would occur as to prevent their use as food additives.

\section{Safety assessment}

The selected five strains were investigated for their safety for use in further studies by determining their bioamine production, mucin degradation, and hemolytic activity. All strains were confirmed as safe bioresources for use as food starters, without any type of bioamine production, mucin degradation, or hemolysis. LAB that are used as probiotic foods or food additives need to satisfy specific safety criteria, such as being negative for mucin degradation, because microbes that degrade mucin can be translocated to other body parts from the intestinal lumen and cause bacteremia (Abe et al. 2010). The hemolytic potential of LAB should also be tested, and it should be confirmed that the tested LAB species are nonhemolytic, as an essential criterion for their use as food additives (Araya et al. 2002). Moreover, the assessment of the ability of LAB strains to produce bioamines, toxic substances generated from the decarboxylation of amino acids present in foods, represents a very important safety test (Bover-Cid and Holzapfel 1999). All strains, tested for antibiotic susceptibility, were found to be susceptible to all the tested antibiotics, except for FB058 which was resistant to tetracycline hydrochloride (Table 3), according to the cut-off value recommended by EFSA (EFSA 2012). The antibiotic susceptibility of LAB strains that are used for human and/or animal consumption represents an essential requirement (Brashears et al. 1998). If bacterial strains with transmissible antibiotic-resistance genes were to be used as food additives, they might lead to the generation of new antibioticresistant pathogens in the host gut, by horizontal gene transfer (EFSA 2012). The MIC values of all of our strains, except for FB058, were below the cut-off values given by EFSA, which indicated their susceptibility to commonly marketed antibiotics: ampicillin, gentamycin, kanamycin sulfate, streptomycin sulfate, erythromycin, and tetracycline hydrochloride.

\section{In Vitro Assessment of the Selected Strains for Survival in the Gastrointestinal Tract}

Every potential LAB strain used in probiotics and probiotic foods to increase their functionalities is expected to show tolerance in the gastrointestinal environment, in order to provide beneficial effects to the host (Shokryazdan et al. 2014). The time interval from the entrance of the food into the gastrointestinal tract to the release from the stomach was reported to be approximately 90 min (Charteris et al. 1998). The ability to tolerate acid, bile, and pancreatic enzymes has been considered a good indicator for the survival of $\mathrm{LAB}$ under gastrointestinal conditions. Acid tolerance represents one of the key factors for selecting $\mathrm{LAB}$ strains, and determines the survival rate of $\mathrm{LAB}$ during their passage through the stomach (Leite et al. 2015). The viabilities of the five selected LAB strains isolated in this study at $\mathrm{pH}-3, \mathrm{pH}-2$, and $\mathrm{pH}-7.2$ (control) are shown in Table 4. All strains, except for FB111, 
Table 2 Identification of five selected LAB strains using 16S rRNA gene sequences

\begin{tabular}{cccc}
\hline \hline Strain & Source & $\begin{array}{c}\text { Accession number of } \\
\text { isolate }\end{array}$ & The nearest matched species from GenBank \\
\hline FB003 & Cabbage kimchi & MF436193 & Lactobacillus plantarum \\
FB058 & Salted squid & MF436194 & Pediococcus pentosaceus \\
FB077 & Squid paste & MF436195 & Weissella viridescens \\
FB081 & Squid paste & MF436196 & Lactobacillus sakei \\
FB111 & Ojingeojeot & MF436197 & L9\% \\
$99 \%$
\end{tabular}

Similarity values were determined using the basic local alignment search tool (BLAST) of the GenBank. Sequences with $97 \%$ similarity to the previously published sequences were used as the criteria to indicate species identity

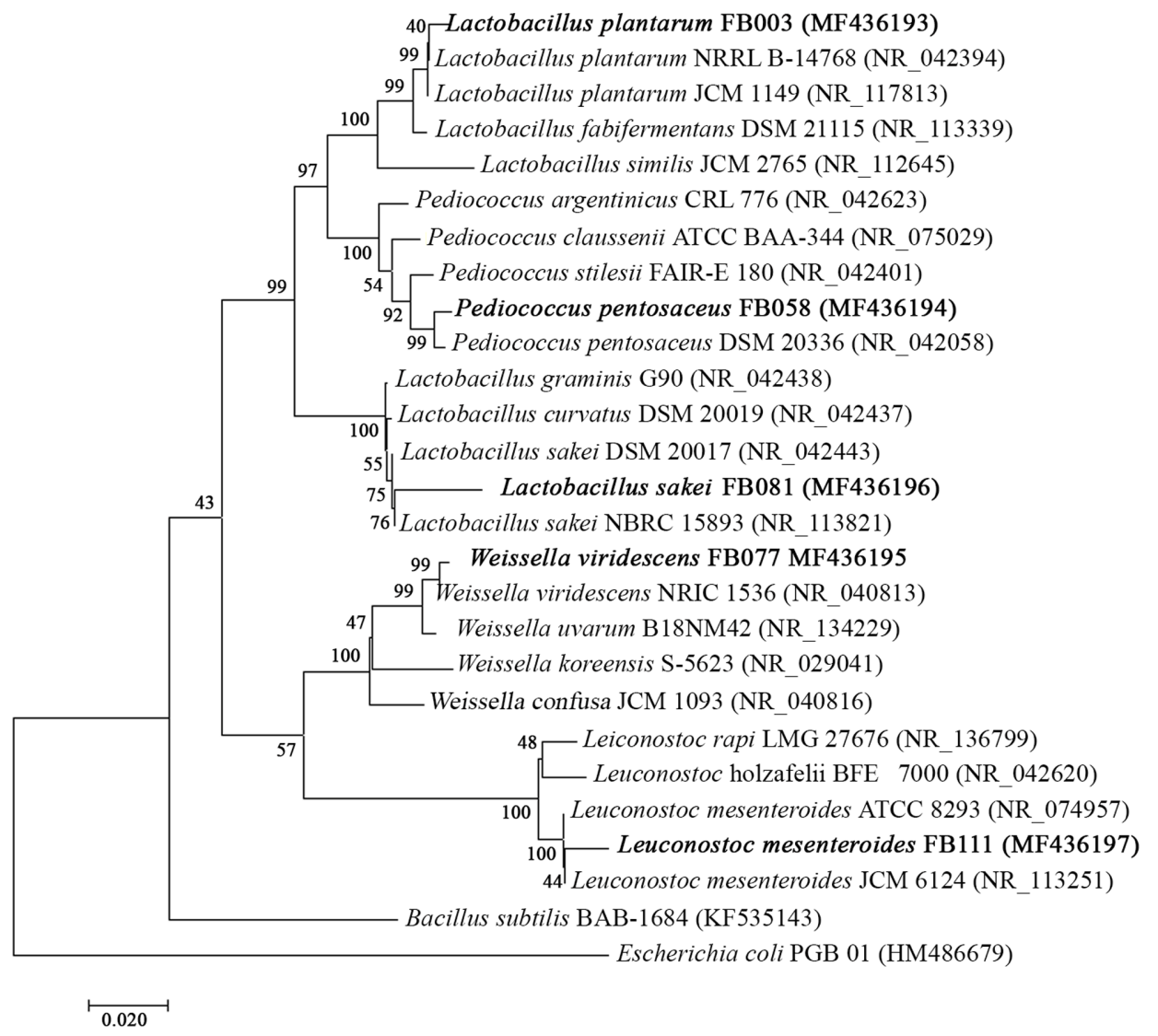

Fig 1 Identification of strains by using phylogenetic tree, constructed based on 16S rDNA sequence of strains isolated from fermented Korean foods. The strains possess $99 \%$ similarity with the corresponding lactic acid bacteria. GenBank accession numbers are indicated in parentheses after the strain name

showed high acidic tolerance at $\mathrm{pH}-3$, with a loss in cell viability of only 0.02 to $0.10 \mathrm{log}$ units, compared to that in the control (which included the same strains at pH-7.2). In FB111, the loss in cell viability was $1.76 \log$ units, significantly $(p \leq 0.05)$ higher than the value of respective strain in the control. The reduction in cell viability for all strains at $\mathrm{pH} 2$ was significantly more pronounced than in the control $(\mathrm{pH}-7.2)$, but this decrease was varied among strains, with the loss in cell viability ranging from 2.43 to $4.64 \log$ units.

All five strains exhibited excellent bile tolerance to $0.3 \%$ bile (oxgall), although the degree of tolerance varied among the strains. FB111 showed the maximum tolerance, with a reduction in cell viability of only $0.05 \mathrm{log}$ units. Other strains also showed significant tolerance, with a reduction in cell viability of 0.21 , $0.43,0.24$, and $0.21 \mathrm{log}$ units for FB003, FB058, FB077, and FB081, respectively (Table 5). The tolerance level of all strains to pancreatic enzymes was also remarkably high, with a loss in cell viability of only $0.13,0.07,0.16,0.21$, and $0.13 \log$ units for FB003, FB058, FB077, FB081, and FB111, respectively (Table 6). In our study, all strains except for FB111 showed high survival, at approximately $80-95 \%$, at $\mathrm{pH}-3$ after a 3-h exposure, while at $\mathrm{pH}-2$, all five strains showed a significant reduction in survival 
Table 3 Minimum inhibitory concentration of antibiotics for five selected strains

\begin{tabular}{|c|c|c|c|c|c|c|}
\hline \multirow[b]{2}{*}{ Antibiotics } & \multicolumn{6}{|c|}{$\mathrm{MIC}(\mathrm{mg} / \mathrm{l})$} \\
\hline & FB003 & FB058 & FB077 & FB081 & FB111 & $\begin{array}{c}\text { Recommended MIC value by } \\
\text { EFSA, } 2012\end{array}$ \\
\hline Ampicillin & $1(\mathrm{~S})$ & $1(\mathrm{~S})$ & $1(\mathrm{~S})$ & $1(\mathrm{~S})$ & $1(\mathrm{~S})$ & $1-4$ \\
\hline Kamamycin sulphate & $8(\mathrm{~S})$ & 64(S) & $8(\mathrm{~S})$ & $8(S)$ & $8(S)$ & $16-64$ \\
\hline Streptomycin sulphate & $4(\mathrm{~S})$ & $16(\mathrm{~S})$ & $8(\mathrm{~S})$ & $4(S)$ & $4(S)$ & $16-64$ \\
\hline Erythromycin & $2(\mathrm{~S})$ & $4(\mathrm{R})$ & $1(\mathrm{~S})$ & $0.25(\mathrm{~S})$ & $0.25(\mathrm{~S})$ & 1 \\
\hline Tetracycline hydrochloride & $2(\mathrm{~S})$ & $2(\mathrm{~S})$ & $0.125(\mathrm{~S})$ & $2(\mathrm{~S})$ & $2(\mathrm{~S})$ & $4-32$ \\
\hline Gentamycin & $1(\mathrm{~S})$ & $32(\mathrm{~S})$ & $32(\mathrm{~S})$ & $16(S)$ & $32(\mathrm{~S})$ & $8-32$ \\
\hline
\end{tabular}

*(S) means susceptible

$*(\mathrm{R})$ means resistance

Table 4 Viability of Selected strains $\left(\log _{10} \mathrm{CFU} / \mathrm{mL}\right)$ after $3 \mathrm{~h}$ exposure to $\mathrm{pH}-7.2$ (control), $\mathrm{pH}-3$ and $\mathrm{pH}-2$

\begin{tabular}{|c|c|c|c|c|c|}
\hline \multirow[b]{2}{*}{ Strains } & \multicolumn{3}{|c|}{ Cell Viability $\left(\log _{10} \mathrm{CFU} / \mathrm{mL}\right)^{1}$} & \multicolumn{2}{|c|}{$\begin{array}{l}\text { Reduction in cell Viability compare to control } \\
\qquad\left(\log _{10} \text { units }\right)^{1}\end{array}$} \\
\hline & pH-7.2 (Control) & $\mathrm{pH}-3$ & $\mathrm{pH}-2$ & $\mathrm{pH}-3$ & $\mathrm{pH}-2$ \\
\hline FB003 & $8.13 \pm 0.005$ & $8.11 \pm 0.007$ & $3.49 \pm 0.003$ & 0.02 & $4.64^{\text {cd }}$ \\
\hline FB058 & $8.11 \pm 0.011$ & $8.01 \pm 0.003$ & $4.39 \pm 0.002$ & 0.1 & $3.72^{\mathrm{bc}}$ \\
\hline FB077 & $7.95 \pm 0.007$ & $7.9 \pm 0.015$ & $4.89 \pm 0.007$ & 0.05 & $3.06^{\mathrm{c}}$ \\
\hline FB081 & $8.00 \pm 0.013$ & $7.95 \pm 0.012$ & $5.57 \pm 0.011$ & 0.05 & $2.43^{\mathrm{b}}$ \\
\hline FB111 & $6.36 \pm 0.004$ & $4.60 \pm 0.005$ & $3.00 \pm 0.003$ & $1.76^{\mathrm{a}}$ & $3.36^{\mathrm{c}}$ \\
\hline
\end{tabular}

${ }^{1}$ Values are means \pm SD of two independent experiments, each with triplicate

${ }^{\mathrm{a}-\mathrm{d}}$ Means within a column with different superscripts are significantly different $(p<0.05)$

Table 5 Viability of Selected isolatesstrains in MRS broth (control) and MRS broth containing $0.3 \%$ bile salt after $4 \mathrm{~h}$ exposure

\begin{tabular}{|c|c|c|c|}
\hline \multirow[b]{2}{*}{ Strains } & \multicolumn{2}{|c|}{ Cell Viability $\left(\log _{10} \mathrm{CFU} / \mathrm{mL}\right)^{1}$} & \multirow{2}{*}{$\begin{array}{l}\text { Reduction in cell } \\
\text { Viability compare to } \\
\text { control ( } \log _{10} \text { units) }\end{array}$} \\
\hline & MRS (Control) & $\begin{array}{c}\text { MRS }+ \\
0.3 \% \text { bile salt }\end{array}$ & \\
\hline FB003 & $8.48 \pm 0.015$ & $8.27 \pm 0.023$ & $0.21^{\mathrm{c}}$ \\
\hline FB058 & $8.51 \pm 0.021$ & $8.08 \pm 0.014$ & $0.43^{\mathrm{bc}}$ \\
\hline FB077 & $8.54 \pm 0.019$ & $8.30 \pm 0.008$ & $0.24^{\mathrm{b}}$ \\
\hline FB081 & $8.51 \pm 0.007$ & $8.30 \pm 0.029$ & $0.21^{\mathrm{b}}$ \\
\hline FB111 & $8.65 \pm 0.024$ & $8.60 \pm 0.019$ & $0.05^{\mathrm{a}}$ \\
\hline
\end{tabular}

${ }^{1}$ Values are means \pm SD of two independent experiments, each with triplicate

${ }^{\mathrm{a}-\mathrm{c}}$ Means within a column with different superscripts are significantly different $(p<0.05)$

$(p \leq 0.05)$. A $0.3 \%$ bile salt tolerance is physiologically significant, since it is considered as the normal bile level encountered in the human intestine (Shokryazdan et al. 2014). A $0.3 \%$ ox bile (oxgall) solution is the most used substitute for human bile salts, used in many studies (Koll et al. 2008). The FB003, FB077 and FB081 strains showed approximately $60 \%$ survival in $0.3 \%$ bile salts, where the maximum survival was observed for FB111 (89\%) and the minimum survival was observed for FB058 (37\%). The survival of bacterial strains in pancreatic enzymes secreted into the small intestine, which are involved in the digestion of proteins, carbohydrates, and fats, represents another important criterion for the selection of starter cultures (Rönkä et al. 2003). The strains used in our experiment showed approximately $\geq 70 \%$ survival in pancreatic enzymes.
Table 6 Viability of selected strains after $3 \mathrm{~h}$ in PBS with and without (control) $1.9 \mathrm{mg} / \mathrm{mL}$ pancreatic enzymes

\begin{tabular}{cccc}
\hline \hline \multirow{2}{*}{ Strains } & \multicolumn{2}{c}{ Cell Viability $\left(\log _{10} \mathrm{CFU} / \mathrm{mL}\right)^{1}$} & \begin{tabular}{c} 
Reduction in cell \\
\cline { 2 - 3 }
\end{tabular} \\
\cline { 2 - 3 } (Control) & $\begin{array}{c}1.9 \mathrm{mg} / \mathrm{mL} \\
\text { Pancreatic } \\
\text { enzymes }\end{array}$ & $\begin{array}{c}\text { Viability compare to } \\
\text { control }\left(\log _{10} \text { units) }\right.\end{array}$ \\
\hline FB003 & $5.45 \pm 0.011$ & $5.32 \pm 0.014$ & $0.13^{\mathrm{b}}$ \\
FB058 & $6.41 \pm 0.019$ & $6.34 \pm 0.017$ & $0.07^{\mathrm{a}}$ \\
FB077 & $6.64 \pm 0.021$ & $6.48 \pm 0.021$ & $0.16^{\mathrm{c}}$ \\
FB081 & $7.42 \pm 0.017$ & $7.21 \pm 0.018$ & $0.21^{\mathrm{bc}}$ \\
FB111 & $6.96 \pm 0.015$ & $6.83 \pm 0.022$ & $0.13^{\mathrm{b}}$ \\
\hline
\end{tabular}

${ }^{1}$ Values are means \pm SD of two independent experiments, each with triplicate

${ }^{\text {a-c }}$ Means within a column with different superscripts are significantly different $(p<0.05)$

\section{Resistance to $\mathrm{NaCl}$ and temperature}

All strains displayed good resistance to all concentrations (2, 4, and $6.5 \%$ ) of $\mathrm{NaCl}$, with little variance. The survival rate of all strains at 15 and $45^{\circ} \mathrm{C}$ were also high (Table 7). Although the $\mathrm{pH}$ range varies in the human stomach, $\mathrm{pH}-3$ is considered as a standard $\mathrm{pH}$ for the investigation of acid tolerance in many studies (Santo et al. 2005). Due to an increased health awareness and changes in appetite, the demand for low sodium jeotgal is increasing. However, in meat and fish fermentation, the addition of salt is the most reliable technique for decreasing water activity and food spoilage (Koo et al. 2016). For this reason, the use of $\mathrm{NaCl}$ resistant strains as starter cultures is necessary. In our experiment, we checked the $\mathrm{NaCl}$ resistance at a concentration of 
Table 7 Resistance of five selected strains to various concentrations of $\mathrm{NaCl}$ and different temperature

\begin{tabular}{cccccc}
\hline \hline \multirow{2}{*}{ Strains } & \multicolumn{3}{c}{$\mathrm{NaCl}$ (Concentration) } & \multicolumn{2}{c}{ Temperature } \\
\cline { 2 - 6 } & $2 \%$ & $4 \%$ & $6.5 \%$ & $15{ }^{\circ} \mathrm{C}$ & $45{ }^{\circ} \mathrm{C}$ \\
\hline FB003 & +++ & +++ & ++ & ++ & +++ \\
FB058 & +++ & +++ & ++ & +++ & +++ \\
FB077 & +++ & +++ & +++ & +++ & +++ \\
FB081 & +++ & +++ & +++ & ++ & +++ \\
FB111 & +++ & +++ & ++ & +++ & +++ \\
\hline
\end{tabular}

+++ , indicates cell viability $>90 \%,++$, indicates cell viability $>80 \%$

Table 8 Antimicrobial activity of selected strains against gram negative and gram positive pathogens

\begin{tabular}{ccccccc}
\hline \hline Pathogens & \multicolumn{5}{c}{ Zone of Inhibition } \\
\cline { 2 - 6 } & FB003 & FB058 & FB077 & FB081 & FB111 \\
\hline $\begin{array}{c}\text { Escherichia coli } \\
\text { K99 KCTC 2617 }\end{array}$ & ++ & ++ & + & ++ & ++ \\
$\begin{array}{c}\text { Shigella boydii KACC 10792 } \\
\text { Staphylococcus aureus }\end{array}$ & ++ & ++ & + & ++ & ++ \\
$\begin{array}{c}\text { KCCM 11335 } \\
\text { Listeria monocytogenes } \\
\text { KACC 10764 }\end{array}$ & +++ & +++ & ++ & +++ & +++ \\
$\begin{array}{c}\text { Yersinia enterocolitica } \\
\text { KACC 15320 }\end{array}$ & +++ & +++ & ++ & +++ & +++ \\
\end{tabular}

+++, $($ diameter $>20 \mathrm{~mm}) ;++,($ diameter $15-20 \mathrm{~mm}) ;+,($ diameter $11-14$ $\mathrm{mm}$ )

2,4 , and $6.5 \%$, and all strains displayed excellent tolerance at all concentrations. Fermented fish products are mainly used to prepare fish sauces and fish pastes (Ibourahema et al. 2008), which omit the cooking procedure involving a very high temperature step. For this reason, we checked the survival of our strains at two different temperatures, 15 and $45^{\circ} \mathrm{C}$ (Menconi et al. 2014), considering the ambient temperature during different seasons. All five strains showed $80-90 \%$ tolerance at both temperatures. Ibourahema et al. (2008) reported that high temperature tolerant bacteria can show rapid growth, increase the production rate of lactic acid, as well as limit the growth of other pathogenic microorganisms.

\section{Antimicrobial activity}

All five strains (FB003, FB058, FB077, FB081, and FB111) inhibited the growth of both gram-negative and gram-positive pathogens, but the degree of inhibition varied among the strains (Table 8). Foodborne pathogenic bacteria can develop in fermented foods. The use of starter cultures with antimicrobial properties could represent a possible solution against pathogenic bacteria. LAB show antimicrobial activity, by producing organic acids, hydrogen peroxide $\left(\mathrm{H}_{2} \mathrm{O}_{2}\right)$, and bacteriocins (Parvez et al. 2006). Bacteriocins compete with pathogens for receptor binding sites, and for available nutrients and growth factors (Yang et al. 2014). All five selected strains displayed a clear zone of inhibition against gram-positive and gram-negative pathogens. A possible reason for the antimicrobial activity exhibited by these strains might be the plantaricin gene, found in FB003, FB077, FB081, and FB111. The antimicrobial activity of FB058 might be based on the production of organic acid.

\section{Changes in $\mathrm{LAB}$ count during fermentation}

The average number of $\mathrm{LAB}$ in fermented samples, in the presence or absence of starter cultures (FB003, FB058, FB077, FB081, and FB111), did not significantly differ on the first day of fermentation. The total LAB count increased proportionally with fermentation time, up to 15 days, in all samples with or without starter cultures, and the degree of variation among all samples was insignificant. However, after 15 days, irrespective of the presence of starter cultures, the LAB count decreased rapidly and significantly $(p \leq 0.05)$ in all samples. At 21 days from the start of fermentation, all samples contained an average of $4 \log$ units of viable LAB cells (Fig. 2). For maintaining consistent quality and safety standards for fermented products, the use of starter cultures in food processing represents a most promising method (Hati et al. 2013). Many studies support the use of LAB, as starter cultures in fermented foods (EFSA 2012). The focus of our study was to identify suitable fermentation starters, that would also increase the bioactivities of fermented squid jeotgal. The number of viable $\mathrm{LAB}$ cells during the fermentation interval is very important, since

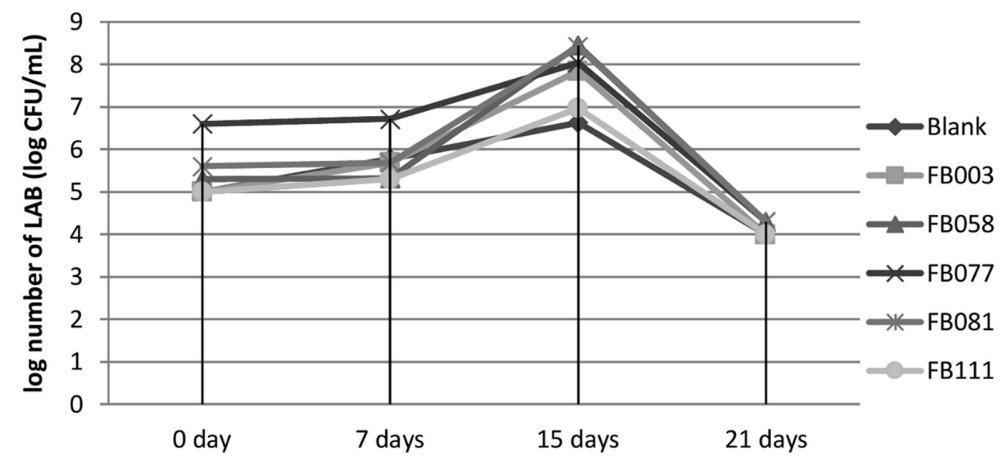

Fig. 2 Changes on average in LAB number (log CFU/mL) in fermented samples at different fermentation time points. Blank, FB003, FB058, FB077, FB081 and FB111 indicate the sample fermented with no starter culture and samples fermented with corresponding LAB strains as starter respectively 

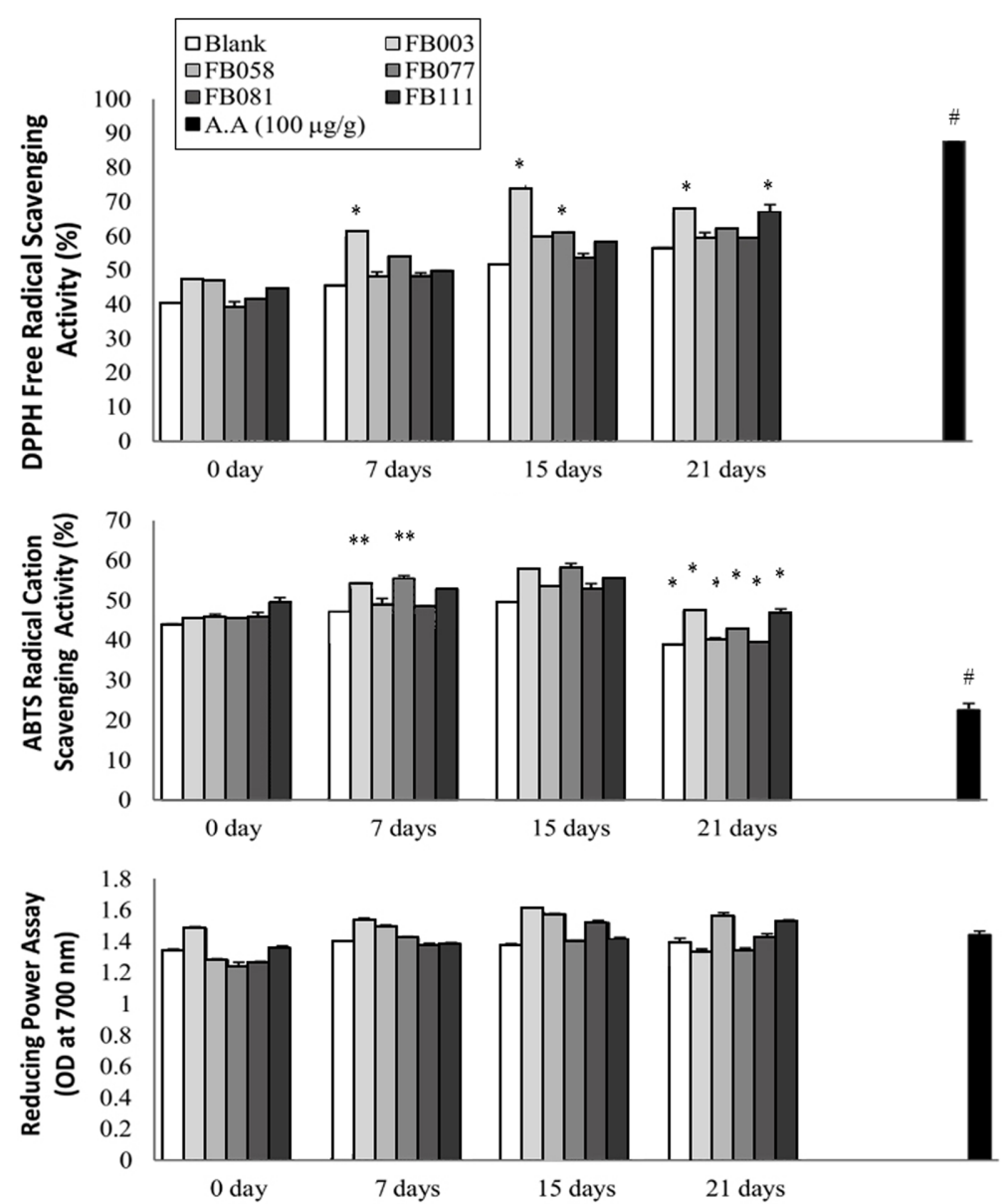

Fig. 3 Results of antioxidant assays of squid jeotgal samples fermented with or without starter culture in various time interval (A) DPPH free radical scavenging activity, (B) ABTS radical cation scavenging assay. (C) Reducing power assay. Results represent the average of three replicates (n=3). Error bars indicate the standard deviation $( \pm \mathrm{SD})$. Ascorbic acid (A.A) is used as positive control in all three assays. \#p $<0.05$, compared with the control; ${ }^{*} p<0.05$, compared with 0 day of each treatment; $* * p<0.01$, compared with 0 day of each treatment

it directly influences the bioactivity of the fermented foods (Mishra et al. 2015). In our study, the total number of viable LAB increased proportionally with time up to 15 days, and showed a direct relationship with the increase in antioxidant activity. The texture, color, and flavor of the samples, with or without starter cultures, were completely unchanged up to 15 days. However, after 15 days all samples started to change their flavor and texture, and at day 21 , the color of the samples also changed. A sharp decrease in the total viable $\mathrm{LAB}$ counts for all samples was also observed on day 21 . No undesirable strains grew in the samples during the fermentation process.

\section{Antioxidant assays}

The disproportionate production of free radicals, that result from metabolic processes in the organism, damages human tissues and is responsible for many diseases. Many beneficial effects for the human body can be achieved by using substances with antioxidant properties (EFSA 2012). The application of probiotic strains with antioxidant activities in foods increases their bioactivity (Shobharani et al. 2013). This study showed that, among all five tested LAB strains, the sample fermented with FB003 (Lactobacillus plantarum) showed the maximum antioxidant activity in all three assays.

The DPPH scavenging activities of fermented samples containing starter cultures considerably differed when compared to the sample without starter cultures. The scavenging activity increased instantly up to $16 \%$ in the FB003 and FB058 fermented samples, while a slight reduction was observed in the FB077 sample. In all fermented samples, including the control sample, the scavenging activity increased gradually with the fermentation time, but the rate of this increase was significantly $(p \leq 0.05)$ lower in the control sample, when compared to the samples fermented with starter cultures. After 7 days, the FB003 and FB077 fermented samples showed a rapid increase in scavenging activity, of approximately 30 and $38 \%$ respectively, when compared to the same activity in the first day samples of the corresponding starter cultures. The 15-day fermented samples showed comparatively higher scavenging activities, approximately 43\% in FB003 while 
after 15 days, some samples started reducing scavenging activity. The percentages of the scavenging activity in 15-day fermented samples were $51.63 \pm 0.023,73.75 \pm 0.031,59.81 \pm 0.009,61.02 \pm$ $0.022,53.51 \pm 0.013$, and $58.23 \pm 0.011 \%$ for the control fermented sample, and the FB003, FB058, FB077, FB081, and FB111 mixtures, respectively (Fig. 3A).

There was no significant difference in the ABTS radical scavenging activity among all samples, with or without starter cultures, in the initial stage of fermentation. All samples showed a proportional increase in scavenging activity with time. However, the control sample displayed an increase in scavenging activity of only about $6 \%$ after 7 days, while increases in the scavenging activity of approximately 20 and $22 \%$ were observed in the FB003 and FB077 samples, respectively. The 15-day fermented samples showed the maximum scavenging activity, but the increases in activity differed among samples. The percentages of scavenging activity in 15-day fermented samples: no addition, FB003, FB058, FB077, FB081, and FB111 were 49.65 \pm 0.015 , $57.98 \pm 0.021,53.45 \pm 0.008,58.17 \pm 0.006,52.75 \pm 0.013$, and 55.54 $\pm 0.016 \%$, respectively (Fig. 3B). The scavenging activities decreased in all fermented samples, up to 21 days.

In the reducing power assay, the sample lacking the starter culture showed a proportional increased in activity with time, but the rate of increase was negligible. All fermented samples containing starter cultures also showed an enhanced reducing power with time. The absorbances of the fermented samples containing the FB003, FB058, FB077, FB081, and FB111 starter cultures at 7 days were $1.534 \pm 0.014,1.496 \pm 0.008,1.418 \pm 0.013,1.372 \pm 0.011$, and $1.383 \pm 0.007$, respectively (Fig. 3C). The fermented samples for all starter cultures displayed the maximum reducing power at 15 days, compared to the fermented control sample. Moreover, FB003 and FB058 showed about 15\% more reducing power than the sample without the starter culture. All fermented samples containing starter cultures showed a decrease in reducing power starting at day 21, except for FB111.

Lactobacillus plantarum has been used as a fermentation starter, and its influence on antioxidant activity has been demonstrated by many studies (Fusco et al. 2015). The sample fermented with FB077 (Weissella viridescens) also showed a significant increase in the DPPH free radical scavenging and the ABTS radical cation scavenging assays, while moderate increases in antioxidant activity were observed in the reducing power assay, when compared to the sample without any starter. Weissella spp. is one of the common LAB species found in fermented kimchi, and is used as a starter culture for various fermented foods, due to its health-promoting activity (Backos et al. 2012). The samples fermented with FB058 (Pediococcus pentosaceus), FB081 (Lactobacillus sakei) and FB111 (Leuconostoc mesenteroides) also showed a gradual increase in antioxidant activity, at different levels, but the increase was not significant compared to the sample without the starter culture.

Sign of completing fermentation can be denoted by physical and chemical changes in the fermented products: especially changes in color, odor and taste. The beneficial effects can be achieved by the decomposition of raw compounds and the formulation of new small peptides. All samples remained unchanged in color, odor and taste up to 15 days. The actual mechanism of the decrease of antioxidant activity after 15 days was not determined. However, the number of LAB count also decreased rapidly after 15 days and the samples of 21 days showed change in color and texture with pungent taste except the sample without starter. This might be occurred due to the degradation of the active compounds responsible for the antioxidant activity.

The data from this study showed that two strains, FB003 (Lactobacillus plantarum) and FB077 (Weissella viridescens), preserved a high viable cell count at a low $\mathrm{pH}$, in the presence of bile salts, and a pancreatic enzyme. Together with their susceptibility to common antibiotics and their antimicrobial activity against pathogenic strains, the samples fermented with these two strains showed maximal antioxidant activity, compared to sample without the starter culture, or the samples containing other strains. Moreover, only the sample fermented with FB003 showed an increase in anticancer activity (data not show). The result suggests that these two strains, FB003 and FB077, can be effectively used as potential starter cultures for the fermentation of squid jeotgal which can reduce the fermentation time by maintain the standard food status and improving the beneficial effects to meet the increasing demand for jeotgal, it is necessary to develop reliable methods that yield a stable and high-quality product in short time. The industrial-scale production of manufactured jeotgal has increased, compared with the production of homemade jeotgal. Therefore, the efforts regarding the research and development of jeotgal, based on the consumers' demand, show that jeotgal has a remarkable potential to be globally recognized as a nutritious and palatable food product. The inoculation of starter cultures during the fermentation process represents one of the best approaches for improving the organoleptic characteristics, safety, shelf life and health benefits (such as antioxidant, anticancer, and anti-obesity effects) of foods, compared with conventionally fermented foods. The addition of starter cultures clearly showed an increase in health benefits in our squid jeotgal samples Therefore, more research will be required to accelerate improvements in sample quality, particularly in the context of industrial-scale production.

Acknowledgments This study was financially supported by Chonnam National University (Grant number: 2016-2846) and the Basic Science Research Program through the National Research Foundation of Korea (NRF) funded by the Ministry of Education (NRF-2017R1D1A3B03027816).

\section{References}

Abe F, Muto M, Yaeshima T, Iwatsuki K, Aihara H, Ohashi Y, Fujisawa T (2010) Safety evaluation of probiotic bifidobacteria by analysis of mucin degradation activity and translocation ability Anaerobe 16: 131-136

Akabanda F, Owusu-Kwarteng J, Tano-Debrah K, Parkouda C, Jespersen L (2014) The use of lactic acid bacteria starter culture in the production of 
Nunu, a spontaneously fermented milk product in Ghana International journal of food science 2014

Araya M, Morelli L, Reid G, Sanders M, Stanton C, Pineiro M (2002) Joint FAO/WHO Working Group report on drafting guidelines for the evaluation of probiotics in food. London, Canada: World Health Organization, Food and Agriculture Organization of the United Nations, New York

Ayeni FA, Sánchez B, Adeniyi BA, Clara G, Margolles A, Ruas-Madiedo P (2011) Evaluation of the functional potential of Weissella and Lactobacillus isolates obtained from Nigerian traditional fermented foods and cow's intestine Int J Food Microbiol 147: 97-104

Backos DS, Franklin CC, Reigan P (2012) The role of glutathione in brain tumor drug resistance Biochem Pharmacol 83: 1005-1012

Bagchi K, Puri S (1998) Free radicals and antioxidants in health and disease: a review East Mediterranean Health Jr 4: 350-360

Borges S, Barbosa J, Silva J, Teixeira P (2013) Evaluation of characteristics of Pediococcus spp. to be used as a vaginal probiotic J Appl Microbiol 115: 527-538

Bover-Cid S, Holzapfel WH (1999) Improved screening procedure for biogenic amine production by lactic acid bacteria Int J Food Microbiol 53: $33-41$

Brashears M, Gilliland S, Buck L (1998) Bile salt deconjugation and cholesterol removal from media by Lactobacillus casei1 J Dairy Sci 81 2103-2110

Brolazo EM, Leite DS, Tiba MR, Villarroel M, Marconi C, Simoes JA (2011) Correlation between API $50 \mathrm{CH}$ and multiplex polymerase chain reaction for the identification of vaginal lactobacilli in isolates Braz $\mathrm{J}$ Microbiol 42: 225-232

Cencic A, Chingwaru W (2010) The role of functional foods, nutraceuticals, and food supplements in intestinal health Nutrients 2: 611-625

Charteris W, Kelly P, Morelli L, Collins J (1998) Development and application of an in vitro methodology to determine the transit tolerance of potentially probiotic Lactobacillus and Bifidobacterium species in the upper human gastrointestinal tract J Appl Microbiol 84: 759-768

Damodharan K, Palaniyandi SA, Yang SH, Suh J-W (2015) In vitro probiotic characterization of Lactobacillus strains from fermented radish and their anti-adherence activity against enteric pathogens Can J Microbiol 61: $837-850$

EFSA P (2012) Panel (EFSA Panel on Plant Protection Products and their Residues), 2013 Guidance on dermal absorption EFSA Journal 10: 2665

Ehrmann M, Kurzak P, Bauer J, Vogel R (2002) Characterization of lactobacilli towards their use as probiotic adjuncts in poultry $\mathrm{J}$ Appl Microbiol 92: 966-975

Frei B (2004) Efficacy of dietary antioxidants to prevent oxidative damage and inhibit chronic disease The journal of Nutrition 134: 3196S-3198S

Fusco V, Quero GM, Cho G-S, Kabisch J, Meske D, Neve H, Bockelmann W, Franz CM (2015) The genus Weissella: taxonomy, ecology and biotechnological potential Frontiers in microbiology 6

Gyamfi MA, Yonamine M, Aniya Y (1999) Free-radical scavenging action of medicinal herbs from Ghana: Thonningia sanguinea on experimentallyinduced liver injuries General Pharmacology: The Vascular System 32: $661-667$

Hajhashemi V, Vaseghi G, Pourfarzam M, Abdollahi A (2010) Are antioxidants helpful for disease prevention? Res Pharm Sci 5: 1

Hati S, Mandal S, Prajapati J (2013) Novel starters for value added fermented dairy products Current Research in Nutrition and Food Science Journal 1: 83-91

Hayek SA, Ibrahim SA (2013) Current limitations and challenges with lactic acid bacteria: a review Food and Nutrition Sciences 4: 73

Ibourahema C, Dauphin RD, Jacqueline D, Thonart P (2008) Characterization of lactic acid bacteria isolated from poultry farms in Senegal African Journal of Biotechnology 7

Koll P, Mändar R, Marcotte H, Leibur E, Mikelsaar M, Hammarström L (2008) Characterization of oral lactobacilli as potential probiotics for oral health Molecular Oral Microbiology 23: 139-147
Koo OK, Lee SJ, Chung KR, Jang DJ, Yang HJ, Kwon DY (2016) Korean traditional fermented fish products: jeotgal Journal of Ethnic Foods 3: 107-116

Kuda T, Kaneko N, Yano T, Mori M (2010) Induction of superoxide anion radical scavenging capacity in Japanese white radish juice and milk by Lactobacillus plantarum isolated from aji-narezushi and kaburazushi Food Chem 120: 517-522

Lee BJ, Kim JS, Kang YM, Lim JH, Kim YM, Lee MS, Jeong MH, Ahn CB, Je JY (2010) Antioxidant activity and ã-aminobutyric acid (GABA) content in sea tangle fermented by Lactobacillus brevis BJ20 isolated from traditional fermented foods Food Chem 122: 271-276

Lee SH, Jung JY, Jeon CO (2014) Microbial successions and metabolite changes during fermentation of salted shrimp (saeu-jeot) with different salt concentrations PLoS One 9: e90115

Leite A, Miguel M, Peixoto R, Ruas-Madiedo P, Paschoalin V, Mayo B, Delgado S (2015) Probiotic potential of selected lactic acid bacteria strains isolated from Brazilian kefir grains J Dairy Sci 98: 3622-3632

Leroy F, De Vuyst L (2004) Lactic acid bacteria as functional starter cultures for the food fermentation industry Trends Food Sci Technol 15: 67-78

Ljungh A, Wadstrom T (2006) Lactic acid bacteria as probiotics Curr Issues Intestinal Microbiol 7: 73-90

Lucio O, Pardo I, Heras J, Krieger-Weber S, Ferrer S (2017) Use of starter cultures of Lactobacillus to induce malolactic fermentation in wine Australian Journal of Grape and Wine Research 23: 15-21

Menconi A, Kallpura G, Latorre JD, Morgan MJ, Pumford NR, Hargis BM, Tellez G (2014) Identification and characterization of lactic acid bacteria in a commercial probiotic culture Bioscience of microbiota, food and health 33: 25-30

Mishra V, Shah C, Mokashe N, Chavan R, Yadav H, Prajapati J (2015) Probiotics as potential antioxidants: a systematic review J Agric Food Chem 63: 3615-3626

Müller D, Carrasco M, Tonarelli G, Simonetta A (2009) Characterization and purification of a new bacteriocin with a broad inhibitory spectrum produced by Lactobacillus plantarum lp 31 strain isolated from dryfermented sausage J Appl Microbiol 106: 2031-2040

Oyaizu M (1986) Studies on products of browning reaction The Japanese Journal of Nutrition and Dietetics 44: 307-315

Parvez S, Malik KA, Ah Kang S, Kim HY (2006) Probiotics and their fermented food products are beneficial for health J Appl Microbiol 100: $1171-1185$

Prapasuwannakul N, Suwannahong K (2015) Chemical composition and antioxidant activity of Klongkone shrimp paste Procedia-Social and Behavioral Sciences 197: 1095-1100

Re R, Pellegrini N, Proteggente A, Pannala A, Yang M, Rice-Evans C (1999) Antioxidant activity applying an improved ABTS radical cation decolorization assay Free Radic Biol Med 26: 1231-1237

Rönkä E, Malinen E, Saarela M, Rinta-Koski M, Aarnikunnas J, Palva A (2003) Probiotic and milk technological properties of Lactobacillus brevis Int J Food Microbiol 83: 63-74

Santo E, Pinho ML, Lisboa C, Alves FG, Martins D, Beirão LH, Sant'anna ES, Franco BDGDM (2005) Effect of different levels of sodium chloride and glucose on fermentation of sardines (Sardinella brasiliensis) by Lactobacillus sakei 2a Brazilian Archives of Biology and Technology 48: 42-52

Serafini M, Del Rio D (2004) Understanding the association between dietary antioxidants, redox status and disease: is the total antioxidant capacity the right tool? Redox report 9: 145-152

Shobharani P, Halami PM, Sachindra N (2013) Potential of marine lactic acid bacteria to ferment Sargassum sp. for enhanced anticoagulant and antioxidant properties J Appl Microbiol 114: 96-107

Shokryazdan P, Sieo CC, Kalavathy R, Liang JB, Alitheen NB, Faseleh Jahromi M, Ho YW (2014) Probiotic potential of Lactobacillus strains with antimicrobial activity against some human pathogenic strains BioMed research international 2014: 927268

Yang J, Ji Y, Park H, Lee J, Park S, Yeo S, Shin H, Holzapfel WH (2014) 
Selection of functional lactic acid bacteria as starter cultures for the fermentation of Korean leek (Allium tuberosum Rottler ex Sprengel.) Int J Food Microbiol 191: 164-171

Zhou J, Gopal P, Gill H (2001) Potential probiotic lactic acid bacteria
Lactobacillus rhamnosus (HN001), Lactobacillus acidophilus (HN017) and Bifidobacterium lactis (HN019) do not degrade gastric mucin in vitro Int J Food Microbiol 63: 81-90 